\title{
Incidence and Risk Factors of Retinopathy of Prematurity (ROP): A Single Center Study in a Tertiary Center in Indonesia
}

\author{
Martono Tri Utomo ${ }^{\mathrm{a} *}$, Aminuddin Harahapa ${ }^{\mathrm{a}}$, Risa Etika ${ }^{\mathrm{a}}$ \\ ${ }^{a}$ Department of Child Health, Faculty of Medicine, Universitas Airlangga/Dr. Soetomo General Academic Hospital, Surabaya, Indonesia \\ Jl. Mayjend Prof. Dr. Moestopo No. 6-8. Surabaya, Jawa Timur, Indonesia 60285 \\ *Corresponding author: Martono Tri Utomo \\ Correspondinge-mail:mrmartono73@gmail.com \\ Corresponding address: Department of Child Health, Faculty of Medicine, Universitas Airlangga/Dr. Soetomo General Academic \\ Hospital, Surabaya, Indonesia. Jl. Mayjend Prof. Dr. Moestopo No. 6-8. Surabaya, Jawa Timur, Indonesia 60285
}

\begin{abstract}
Background: Retinopathy of prematurity (ROP) is an abnormal proliferative retinal blood vessel in premature infants. ROP is known as one of the causes of blindness in children in developed countries.

Objectives: We conducted this study to report the incidence and identify the potential risk factors associated with ROP.

Methods: This study was a hospital-based retrospective cohort study of preterm infants in the tertiary neonatal intensive care unit from May 2009 to April 2011. The ROP was identified by an ophthalmologist with binocular indirect ophthalmoscope (BIO). Potential risk factors such as gestational age, birth weight, oxygen therapy, sepsis, small for gestational age, blood transfusion, asphyxia, and respiratory distress syndrome were analyzed using the bivariate and multivariate analysis.
\end{abstract}

Results: There were 248 preterm infants enrolled in this study. Thirty-two (12.9\%) patients were diagnosed with various ROP stages, and $43.7 \%$ patients suffer from severe ROP requiring treatment for severe ROP. Gestational age and birth weight were not independent risk factors of ROP. In contrast, oxygen therapy (OR 36.93, CI 4.73-288.02), sepsis (OR 4.86, CI 1.85-12.82), and small for gestational age (OR 3.99, CI 1.47-10.82) include as independent risk factors.

Conclusions: Incidence of ROP were $12.9 \%$, while the independent risk factors were oxygen therapy, sepsis, and small for gestational age.

Keywords: binocular indirect opthalmoscope; blindess; premature; risk factors; retinopathy of prematurity 


\section{Introduction}

Retinopathy of prematurity (ROP) is a retinal disorder resulting from the disruption of normal retinal vascular development. Vasoconstriction and obliteration of the capillary bed followed by neovascularization towards the vitreous causes retinal edema, retinal hemorrhages, fibrosis, and traction, eventually resulting in retinal detachment.[1] The disease has been extensively studied worldwide due to increased survival rates among very low birth weight preterm newborns (NBs) (birth weight (BW) $\leq 1500$ g) who are at the highest risk for developing ROP. The high rates lead to a significant rise of other comorbidities related to preterm birth that have a significant social impact, i.e., blindness secondary to ROP.[2]

Globally, in 2010, an estimated 184,700 of 14.9 million preterm babies suffer from the various stage of ROP, of whom 20,000 were blind. While in high-income countries, approximately 6,300 of 32,700 babies with ROP require treatment, and 1,700 babies were blind or severely visually impaired from ROP.[3] The World Health Organization's VISION 2020 program has identified ROP as an essential cause of blindness in both high- and middle-income countries.[4]

ROP incidence and severity are inversely related to gestational age (GA) or BW of the infant. Approximately $65 \%$ of the infant with BW $<1250 \mathrm{~g}$ and $80 \%$ of those with $\mathrm{BW}<1000 \mathrm{~g}$ will develop ROP.[5] Approximately 2\% of the infant with BW 1000-1250 g and 16\% with BW $<750$ will suffer threshold stage 3+ disease which eligible for treatment.[1] ROP is a multifactorial disease.[5] ROP has been related to hyperoxemia, although the exact mechanism of ROP with high oxygenation alone was not well known. Other various risk factors that have been identified including extreme prematurity, sepsis, blood transfusion, anemia, intraventricular hemorrhage, small for gestational age (SMG), respiratory distress syndrome (RDS), postnatal weight gain, and insulin-like growth factor 1 (IGF-1).[1,5,6] Identification of the risk factors and determine the etiology may help neonatologists and ophthalmologists to establish an accurate diagnosis and prevent the disease progression.[7]

\section{Subjects and Methods}

This cohort retrospective study was conducted in the Neonatal Intensive Unit (NICU) from May 2009 to April 2011. This study's inclusion criteria were premature infants born at gestational age $<37$ weeks and birth weight $<2500$ grams. The exclusion criteria including: 1) infant who passed away before sufficient eye examinations for diagnosis of ROP, 2) infants who were not referred for eye examination although they met the inclusion criteria, 3) infant who was loss to follow-up before sufficient eye examination for either rule out ROP or identify the progression/regression of established ROP.

The premature infants who met the criteria underwent the initial eye examinations on their 4th-7th week of life. All eye examination was performed by the ophthalmologist who has certification for ROP examination with BIO. The stages of ROP were classified according to the International Classification of Retinopathy. The 
opthalmologist would repeat the tests every two weeks if the ROP were not found in the initial assessment. The screening intervals were dependent on the disease's severity until the retina was fully vascularised or the infant developed threshold ROP. All infants who develop threshold ROP were treated with laser therapy.

The data was analyzed using Statistical Package for the Social Science (SPSS) version 17.0. Categorical variables were reported as counts and percentages. Univariate logistic regression was used to identify potential risk factors of ROP. The results present as frequencies, means \pm standard deviation (SD), and $p$ values. P-value $<0.25$ was considered statistically significant. Multiple logistic regression analyses were performed to determine the independent predictors of the development of ROP. Unadjusted, as well as adjusted odds ratios were recorded with a $95 \%$ confidence interval. $P$-value $<0,05$ was considered statistically significant.

\section{Results}

Of 430 preterm infants enrolled in this study, 253 (58.8\%) infants met the inclusion criteria. Meanwhile, the 177 (41.2\%) infants were excluded: 56 (13.0\%) infants died before the ROP examination, 51 (11.9\%) infants discharged on request, 50 (11.6\%) infants absent for outpatient ophthalmologist control schedule, and $20(4.7 \%)$ infants were suffering from severe congenital abnormalities. The 253 infants underwent a BIO eye examination at the Department of Ophthalmology. However, four preterm infants lost to follow-up during the observation, and one infant died before the observation period was completed (42 weeks). During the two years of the study, the total sample was 248 premature infants. From the BIO examination results, 32 infants (12.9\%) had ROP, and the remaining 216 (87.1\%) infants had no signs of ROP. The incidence of ROP in this study was $12.9 \%$. The flowcharts of the study participants were shown in Figure 1.

Most of the patients with ROP were level 1 and 2 (75\%), level 3 was 6 (18.7\%), and only 2 (6.3\%) were levels 4 and 5. Plus disease, which associates with severe ROP, was found in 14 cases (43.7\%) and absent in the remaining 18 cases (56.3\%). In this study, most patients (56.3\%) experienced spontaneous regression, while the remaining 14 patients $(43.7 \%)$ require laser treatment. None of the patients with ROP required surgery during the study period.

Table 1 shows results of mean GA of the study subjects was $32.2 \pm 2.5$ weeks (range 24-36) weeks. The mean GA of preterm infants with ROP was 30.8 \pm 2.9 weeks (range 24-36) weeks, while the group of preterm infants who did not suffer ROP was $32.5 \pm 2.3$ weeks (range 25-36) weeks. In the 36 weeks GA group, there was a $10.0 \%$ incidence of ROP, while two preterm infants in the 24 weeks GA group did not suffer from ROP. ROP incidence in the GA $<32$ weeks group was 19 (25.3\%), while those without ROP were 56 (74.7\%). On the other hand, in the GA above or equal to 32 weeks group, there were 13 (7.5\%) suffered from ROP while the remaining 160 (92.5\%) did not suffer from ROP. The mean BW of preterm infants in this study was $1670.1 \pm 344.2 \mathrm{~g}$ (range 760-2450) g. The mean BW of ROP patients was $1376.9 \pm 341.6 \mathrm{~g}$ (range 760-2300) g, 
and the mean BW without ROP was $1713.6 \pm 323.4 \mathrm{~g}$ (range 1000-2400) g. A total of four preterm infants under $1000 \mathrm{~g}$ and one preterm infant with BW $2300 \mathrm{~g}$ were suffered from ROP.

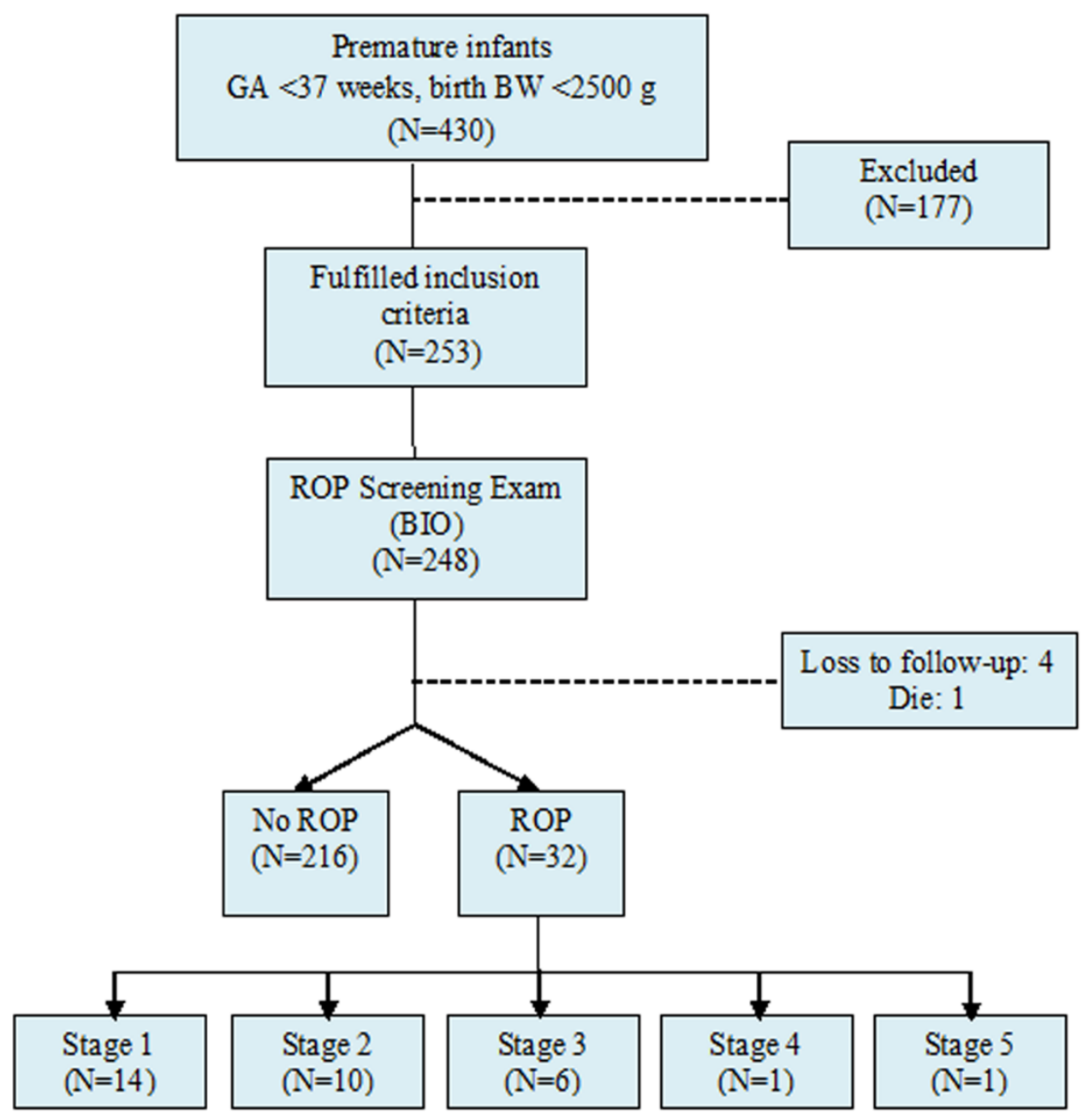

Fig. 1. Schematic diagram of the study 
Table 1. Subject characteristics

\begin{tabular}{|c|c|c|c|}
\hline \multirow[t]{2}{*}{ Characteristics } & \multicolumn{2}{|c|}{ ROP } & \multirow{2}{*}{$\begin{array}{c}\text { Total } \\
\text { N }\end{array}$} \\
\hline & n(\%) & $\mathbf{n}(\%)$ & \\
\hline \multicolumn{4}{|l|}{ Sex } \\
\hline Male & $12(9.1)$ & $120(90.9)$ & 132 \\
\hline Female & $20(17.2)$ & $96(82.8)$ & 116 \\
\hline \multicolumn{4}{|l|}{ GA (weeks) } \\
\hline$<28$ & $6(28,6)$ & $15(71,4)$ & 21 \\
\hline 29 & $2(20,0)$ & $8(80,0)$ & 10 \\
\hline 30 & $7(30,4)$ & $16(69,6)$ & 23 \\
\hline 31 & $4(19,0)$ & $17(81,0)$ & 21 \\
\hline 32 & $6(11,5)$ & $46(88,5)$ & 52 \\
\hline 33 & $0(0,0)$ & $28(100,0)$ & 28 \\
\hline 34 & $4(8,7)$ & $42(91,3)$ & 46 \\
\hline 35 & $1(3,7)$ & $26(96,3)$ & 27 \\
\hline 36 & $2(10,0)$ & $18(90,0)$ & 20 \\
\hline \multicolumn{4}{|l|}{ BW (grams) } \\
\hline 750-999 & $4(100,0)$ & $0(0,0 \%)$ & 4 \\
\hline $1000-1249$ & $8(36,4)$ & $14(63,6)$ & 22 \\
\hline $1250-1499$ & $4(8,9)$ & $41(91,1)$ & 45 \\
\hline $1500-1749$ & $12(16,9)$ & $59(83,1)$ & 71 \\
\hline $1750-2000$ & $3(4,5)$ & $63(95,5)$ & 66 \\
\hline$\geq 2000$ & $1(2,5)$ & $39(97,5)$ & 40 \\
\hline
\end{tabular}

Table 2 shows that GA less than 32 weeks, BW less than $1501 \mathrm{~g}$, oxygen therapy, sepsis, SGA, history of transfusion, and RDS were statistically significant $(\mathrm{p}<0.25)$, considered ROP incidence's potential factors. Meanwhile, asphyxia was not statistically significant $(\mathrm{p}>0.25)$ and was not considered to have a potential effect on the ROP incidence. In the multiple logistic regression analysis, only three factors were statistically significant, i.e., oxygen therapy ( $\mathrm{p}=0.001 ; \mathrm{OR}=36.93$; CI 95\% 4.73 to 288.02), sepsis ( $\mathrm{p}=0.001 ; \mathrm{OR}=4.86$; CI $95 \% 1.84$ to 12.82 ), and SGA ( $\mathrm{p}=0.007 ; \mathrm{OR}=3.99$; CI $95 \% 1.47$ to 10.82 ). Meanwhile, gestational age, birth weight, blood transfusion, and RDS were not statistically significant ( $\mathrm{p}>0.05)$ (Table 3). 
Table 2. Univariate analysis of ROP potential risk factors

\begin{tabular}{|c|c|c|c|}
\hline \multirow[t]{2}{*}{ Risk Factors } & \multicolumn{2}{|c|}{ ROP } & \multirow[t]{2}{*}{$p$} \\
\hline & Yes n(\%) & No n(\%) & \\
\hline \multicolumn{4}{|l|}{ GA $<32$ weeks } \\
\hline Yes & $19(25,3)$ & $56(74,7)$ & $<0,001$ \\
\hline No & $13(7,5)$ & $160(92,5)$ & \\
\hline \multicolumn{4}{|l|}{$\mathrm{BW}<1501 \mathrm{~g}$} \\
\hline Yes & $22(23,4)$ & $72(76,6)$ & $<0,001$ \\
\hline No & $10(6,5)$ & $144(93,5)$ & \\
\hline \multicolumn{4}{|c|}{ Oxygen therapy } \\
\hline Yes & $31(32,0)$ & $66(68,0)$ & $<0,001$ \\
\hline No & $1(0,7)$ & $150(99,3)$ & \\
\hline \multicolumn{4}{|l|}{ Sepsis } \\
\hline Yes & $18(43,9)$ & $23(56,1)$ & $<0,001$ \\
\hline No & $14(6,8)$ & $193(93,2)$ & \\
\hline \multicolumn{4}{|l|}{ SGA } \\
\hline Yes & $15(25,4)$ & $44(74,6)$ & 0,002 \\
\hline No & $17(9,0)$ & $171(90,9)$ & \\
\hline \multicolumn{4}{|c|}{ Blood transfusion } \\
\hline Yes & $13(40,6)$ & $19(59,4)$ & $<0,001$ \\
\hline No & $19(8,8)$ & $197(91,2)$ & \\
\hline \multicolumn{4}{|l|}{ Asphyxia } \\
\hline Yes & $3(15,8)$ & $16(84,2)$ & 0,697 \\
\hline No & $29(12,7)$ & $200(87,3)$ & \\
\hline \multicolumn{4}{|l|}{ RDS } \\
\hline Yes & $21(30,9)$ & $47(69,1)$ & $<0,001$ \\
\hline No & $11(6,1)$ & $169(93,9)$ & \\
\hline
\end{tabular}

Table 3. Independent risk factors of ROP based on multiple logistic regression analysis

\begin{tabular}{lcccc}
\hline Risk Factors & $\boldsymbol{\beta}$ & $\boldsymbol{p}$ & OR & CI 95\% \\
\hline GA $<\mathbf{3 2}$ weeks & 0,872 & 0,06 & 2,39 & $0,94-6,07$ \\
BW $<\mathbf{1 5 0 0} \mathbf{g}$ & 0,108 & 0,842 & 1,11 & $0,39-3,21$ \\
Oxygen therapy & 3,609 & 0,001 & 36,93 & $4,73-288,02$ \\
Sepsis & 1,582 & 0,001 & 4,86 & $1,85-12,82$ \\
SGA & 1,384 & 0,007 & 3,99 & $1,47-10,82$ \\
Blood transfusion & 0,165 & 0,776 & 1,18 & $0,38-3,66$ \\
RDS & 0,482 & 0,328 & 1,62 & $0,62-4,25$ \\
\hline
\end{tabular}




\section{Discussion}

This study showed that the incidence of ROP in premature infants was $12.9 \%$. The incidence rate was lower compared to previous studies. The Vermont Oxford Network database, which collects data from $>1000$ NICUs worldwide, estimated the incidence of ROP was 33.2\% in neonates with BW $<1500$ g.[8] Akkawi MT et al. reported that the ROP incidence and severe stage 1 ROP requiring treatment were $23.5 \%$ and $11.3 \%$, respectively.[9] In India, a comparable country to Indonesia in terms of socioeconomic aspects, Patel SS et al. reported that the ROP efficacy rate was $24.1 \%$.[10] ROP incidence were varied depending on the inclusion criteria, neonatal care quality, and population heterogeneity. Some risk factors were well established (GA, BW). However, another risk is not well-known.[11] These variations may be due to a lack of access to advanced neonatal care units in many parts of developed and underdeveloped countries.[12] Read the study carefully while comparing the reports due to differences in methodologies and selection criteria.[13] The variety of ROP incidence showed in Table 4.

Numerous ROP studies only include $<32$ weeks of gestation infants or BW $<1500$ g.[14] Current screening criteria in the United States and many developed countries are base on GA and BW at delivery.[15,16] According to the most recent American Academy of Pediatrics (AAP) guidelines, screening examinations for ROP are recommended for all infants born at a GA $\leq 30$ weeks or with a BW $\leq 1500 \mathrm{~g}$, as well as for those who born at GA $>30$ weeks with BW between $1500 \mathrm{~g}$ and $2000 \mathrm{~g}$ with an unstable clinical course.[15] In middle-income countries, this scenario is significantly varies depending on the birth conditions and survival rates of premature infants. ROP can occur in much older and bigger infants in middle-income than in high-income countries due to various neonatal care standards.[17] In this study, we included infants with $\mathrm{BW}>1500 \mathrm{~g}$ or $>32$ weeks of gestation. Our inclusion criteria were preterm infants $<37$ weeks' gestation and $\mathrm{BW}<2500 \mathrm{~g}$.

Gilbert et al. suggested that the ROP in highly developed countries differs from ROP in less developed countries. However, notice that: 1) most published data of ROP are from selected NICU series, and 2) due to the intensive care setting, these types of series are rarely valid in population and epidemiology.[18] In this study, the low incidence of ROP was related to the inclusion criteria (GA $<37$ weeks and BW $<2500 \mathrm{~g}$ ), and data were taken from all newborn care rooms. Besides, the number of preterm infants (177 infants) who met the inclusion criteria should be excluded from the study for various reasons, possibly affect the ROP incidence. The wide range of ROP incidence from various existing studies was probably due to differences in neonatal facilities standards in different countries. In theory, the increase in ROP incidence causes by the higher life expectancy of preterm infants. Besides, the decrease in the ROP incidence is due to a higher knowledge of neonatal pathophysiology, the presence of surfactants proven to improve lung maturity, pulse oximetry uses for control oxygen and antenatal steroids use.[19] 
Tabel 4. Studies of ROP incidence and risk factors

\begin{tabular}{|c|c|c|c|c|c|c|}
\hline Author & Country & $\begin{array}{c}\text { Year of } \\
\text { Publication }\end{array}$ & $\begin{array}{c}\text { GA } \\
\text { (week) }\end{array}$ & $\begin{array}{c}\text { BW } \\
\text { (gram) }\end{array}$ & $\begin{array}{r}\text { ROP } \\
(\%)\end{array}$ & Independent risk factors \\
\hline [20] & Kuwait & 2000 & $<34$ & $>1500$ & 19.1 & None \\
\hline [21] & India & 2004 & $\leq 35$ & $\leq 1500$ & 21.7 & oxygen therapy, apnea, sepsis \\
\hline$[22]$ & Indonesia & 2005 & $<37$ & $<2500$ & 26.0 & $\begin{array}{l}\text { asphyxia, multiple, sepsis, blood } \\
\text { transfusions, and oxygen therapy }\end{array}$ \\
\hline [13] & Pakistan & 2008 & $\leq 32$ & $\leq 1500$ & 32.4 & GA, sepsis, RDS \\
\hline [12] & Iran & 2010 & $<37$ & $\leq 1500$ & 19.0 & GA, blood transpusion \\
\hline [23] & China & 2011 & $<30$ & $<1501$ & 47.0 & $\begin{array}{l}\text { sepsis, oxygen ex-posure, and low } \\
\text { GA }\end{array}$ \\
\hline [24] & India & 2016 & $\leq 30$ & $\leq 1500$ & 28.57 & $\begin{array}{l}\text { sepsis, prematurity, } \\
\text { RDS, apnea, BW, GA, red blood } \\
\text { cell transfusions }\end{array}$ \\
\hline$[25]$ & Turkey & 2018 & $\leq 32$ & $\leq 2500$ & 27.0 & $\begin{array}{l}\text { BW, GA, oxygen therapy, sepsis, } \\
\text { red blood cell transfusions }\end{array}$ \\
\hline [26] & Ghana & 2020 & $\leq 32$ & $\leq 1500$ & 13.7 & $\begin{array}{l}\text { sepsis, nasogastric } \\
\text { tube feeding, poor pupil dilation, } \\
\text { oxygen therapy }\end{array}$ \\
\hline [27] & Saudi Arabia & 2020 & $<34$ & $<1500$ & 33.3 & None \\
\hline
\end{tabular}

Some studies identified oxygen therapy, anemia, double volume exchange, packed cell volume transfusion, septicemia, apnea, and sepsis as important risk factors. Parekh et al. found that oxygen therapy, ventilation, RDS, blood transfusion, apnea, surfactant, low birth weight, low gestational age were significant ROP risk factors. However, in multivariate analysis, only RDS, blood transfusion, apnea, low BW, and low GA (prematurity) are independent and significant.[24] Besides, Al Essa et al. and AlBalawi HB et al. reported no independent and significant ROP risk factors found in their study.[20,27] Summary of independent risk 
factors that can affect ROP presented in Table 4. In this study, the univariate analysis showed a significant relationship between GA, BW, oxygen therapy, blood transfusion, RDS, sepsis, and SGA (Table 2) on ROP incidence, in line with previous studies. However, in multiple logistic regression analysis, only oxygen therapy, sepsis, and SGA were independent predictors of ROP development. Although prematurity is wellestablish as the most significant risk factor in ROP development, this study showed that both GA and BW were not independent predictors of ROP.[13] These findings explained the critical role of the environment affect the progression of ROP.

The differences of independent risk factors in the various studies mentioned above depend on the inclusion criteria, neonatal care facilities, and the ability to control risk factors.[21] Besides, with the low life expectancy of preterm infants with very low birth weight, the ROP may not be identified because the patient died before the examination.[22] Similar situation happened in this study, where the mortality rate of preterm infants with very low BW was still high. Taqui et al. reported that ROP could occur in preterm infants with higher BW and GA in developing and underdeveloped countries, which probably causes by uncontrolled infection, oxygen consumption, and other risk factors.[13] The ability to identify post-natal risk factors as predictors of ROP is beneficial for screening programs.[27] In this study, we found that independent risk factors as predictors of ROP were oxygen therapy, sepsis, and small gestational age.

Gestational age, BW, and post-natal oxygen supplementation are major independent risk factors of ROP.[28] The use of supplemental oxygen, oxygen concentration, duration, and prolonged mechanical ventilation were the most frequent risk factors of severe and treatment-requiring ROP.[7] This study is similar to previous studies regarding oxygen therapy's role in ROP, although the oxygen saturation was not controlled and documented. The altered regulation of vascular endothelial growth factor from repeated episodes of hyperoxemia and hypoxia is an important factor in the pathogenesis of ROP.[29] Ebrahim M et al. reported that there was no relationship between oxygen therapy and ROP. However, their study overemphasized the oxygen roles, and no excessive oxygen administration was identified in their neonatal services.[12]

Multiple studies have reported that neonatal sepsis plays a role in the development of ROP.[30,31] Sepsis is an independent predictor of ROP development in many Asian studies, including in Indonesian studies.[22] Patel SS et al. stated that sepsis was a highly significant risk factor. Linear regression analysis showed that septicemia alone was an independent risk factor in the etiology of ROP.[10] Our study also found that sepsis was an independent risk factor in the development of ROP. Sepsis plays a role through cytokines and endotoxins, which directly affect retinal angiogenesis. This process is frequently accompanied by hypotension, which causes impairment of tissue perfusion and retinal ischemia.[3] Sepsis is a risk factor of ROP, especially severe sepsis due to the pro-inflammatory mediators that affect the vessels' endothelium (it may occur in the retinal vessels that interrupt the normal growth of the retina).[32]

Some previous studies have reported that ROP prevalence was higher in SGA infants than appropriate for 
GA preterm, while SGA was not a risk factor for ROP in other reports.[33,34] SGA have greater risks of any ROP $(90 \%$ vs $58 \%, \mathrm{p}<0,01)$. In a multivariate regression model, both SGA and BW $<35$ th percentile for GA (growth restriction) was associated with increased risks of threshold ROP (relative risk: 3.7 and 4.5, respectively).[35] Factors that are considered an increased risk for severe ROP in SGA infants were chronic uterine hypoxia, abnormal growth factor levels, nutrient restriction, and antioxidant deficiency.[36] Bas et al. reported SGA was associated with a decreased incidence of severe ROP in VLBW infants.[25] However, in our study, SGA was associated with an increased incidence of ROP in preterm infants.

We also found ROP among infants with a higher range of GA and BW. Since the range of GA and BW of ROP patients in developing countries are higher than those in underdeveloped countries, we suggest performing ROP screening in the infant with $<37$ weeks GA and $<2500 \mathrm{~g} \mathrm{BW}$ with consideration of some risk factors such as oxygen therapy, sepsis, and SGA.[18] These facts require nationwide attempts to improve public awareness and collaborate with the referral hospital for premature infants screening programs. Our study had several limitations, i.e., a small sample size and the limitation to identify other risk factors in premature infants.

\section{Conclusion}

The incidence of ROP is $12.9 \%$. The independent predictor of ROP are oxygen therapy, sepsis, and SGA. Current study suggests that screening criteria for ROP particularly in this institution are GA $<37$ weeks and BW $<2500$ g.

Competing interest: All authors declare no conflict of interest.

Funding: This research did not receive any specific grant from funding agencies in the public, commercial, or not-for-profit sectors.

Ethical Standard: This study obtained permission from the Institutional Ethical Committee of Dr. Soetomo General Academic Hospital (No. 48/Panke.KKE/III/2011).

\section{References}

[1] Gomella T. Retinopathy of Prematurity. Neonatology: Management, Procedures, On-Call Problem, Diseases, and Drugs. 8th ed., New York: McGraw-Hill Companies Inc.; 2020, p. 1051-6.

[2] Fortes Filho J, Eckert G, Valiatti F, da Costa M, Bonomo P, Prociano R. Prevalence of retinopathy of prematurity: an institutional crosssectional study of preterm infants in Brazil. Rev Panam Salud Publica 2009;26:216-20.

[3] Blencowe H, Lawn J, Vazquez T. Preterm-associated visual impairment and estimates of retinopathy of prematurity at regional and global levels for 2010. Pediatr Res 2013;17:35-49.

[4] Gilbert C, Foster A. Childhood blindness in the context of VISION, 2020 The right to sight. Bulletin World Health Organization 2010;79:227-32.

[5] Leeman K, VanderVeen D. Retinopathy of Prematurity. Cloherty and Stark's Manual of Neonatal Care. 8th ed., Philadelphia: Wolters Kluwer Medknow Publications; 2017, p. 986-92.

[6] Smith L. Pathogenesis of retinopathy of prematurity. Semin Neonatol 2003;8:469-473.

[7] Kim S, Port A, Swan R, Campbell J, Chan R, Chiang M. Retinopathy of Prematurity: A Review of Risk Factors and their Clinical 
Significance. Survey of Ophthalmology 2018. https://doi.org/10.1016/j.survophthal.2018.04.002.

[8] Cavallaro G, Filippi L, Bagnoli P, La Marca G, Cristofori G, G Raffaeli. The pathophysiology of retinopathy of prematurity: an update of previous and recent knowledge. Acta Ophthalmol 2014;92:2-20.

[9] Akkawi M, Shehadeh M, Shams A. Incidence and risk factors of retinopathy of prematurity in three neonatal intensive care units in Palestine. BMC Ophthalmology 2019;19:189.

[10] Patel S, Shendurnikar N. Retinopathy of prematurity in India: incidence, risk factors, outcome and the applicability of current screening criteria. Int J Contemp Pediatr 2019;6:2235-41.

[11]Freitas A, Mörschbächer R, Thorell M, Rhoden E. Incidence and risk factors for retinopathy of prematurity: a retrospective cohort study. International Journal of Retina and Vitreous 2018;20.

[12] Ebrahim M, Ahmad R, Mohammad M. Incidence and risk factors of retinopathy of prematurity in Babol, North of Iran. Ophthalmic Epidemiology 2010;17:166-70. https://doi.org/10.3109/09286581003734860.

[13] Taqui A, Syed R, Chaudhry T, Ahmad K, Salat M. Retinopathy of prematurity: frequency and risk factors in a tertiary care hospital in Karachi, Pakistan. J Pak Med Assoc 2008;58:186-90.

[14] Gonçalves E, Násser L, Martelli D, Alkmim I, Mourão T, Caldeira A, et al. Incidence and risk factors for retinopathy of prematurity in a Brazilian reference service. Sao Paulo Med J 2014;132:85-91. https://doi.org/10.1590/1516-3180.2014.1322544.

[15]Fierson W, AMERICAN ACADEMY OF PEDIATRICS Section on Ophthalmology; AMERICAN ACADEMY OF OPHTHALMOLOGY; AMERICAN ASSOCIATION FOR PEDIATRIC OPHTHALMOLOGY AND STRABISMUS; AMERICAN ASSOCIATION OF CERTIFIED ORTHOPTISTS. Screening Examination of Premature Infants for Retinopathy of Prematurity. Pediatrics 2018;142:e20183061. https://doi.org/10.1542/peds.2018-3061.

[16] Wilkinson A, Haines L, Head K, Fielder A. UK retinopathy of prematurity guideline. Eye 2009;23:2137-2139.

[17]Zin A, Cole G. Retinopathy of prematurity-incidence today. Clin Perinatol 2013;40:185-200. https://doi.org/10.1016/j.clp.2013.02.001.

[18] Gilbert C, Fielder A, Gordillo L, Quinn G, Semiglia R, Visintin P, et al. Characteristics of infants with severe retinopathy of prematurity in countries with low, moderate, and high levels of development: implications for screening programs. Pediatrics 2005;115:e518-25. https://doi.org/10.1542/peds.2004-1180.

[19] Chiang M, Arons R, Flynn J, Starren J. Incidence of retinopathy of prematurity from 1996 to 2000: analysis of a comprehensive New York state patient database. Ophtalmology 2004;111:1317-25. https://doi.org/10.1016/j.ophtha.2003.10.030.

[20] Al-Essa M, Rashwan N, Al-Ajmi M. Retinopathy of prematurity in infants with birth weight above 1500 grams. East African Medical Journal 2000;77:562-4. https://doi.org/10.4314/eamj.v77i10.46713.

[21] Gupta V, Dhaliwal U, Sharma R, Gupta P, Rohatgi J. Retinopathy of prematurity--risk factors. Indian J Pediatr 2004;71:887-92. https://doi.org/10.1007/BF02830827.

[22] Rohsiswatmo R. Retinopathy of prematurity: Prevalence and risk factors. Paediatrica Indonesiana 2005;45:270-4.

[23]Chen M, Citil A, McCabe F, Leicht K, Fiascone J, Dammann C, et al. Infection, oxygen, and immaturity: interacting risk factors for retinopathy of prematurity. Neonatology 2011;99:125-32.

[24]Parekh A, Behera M, Kulkarni S, Narwadkar P, Natu S. Retinopathy of prematurity: a study of incidence and risk factors. International Journal of Contemporary Pediatrics 2016;3:1320-5.

[25]Bas A, Demirel N, Koc E, Ulubas Isik D, Hirfanoglu İ, Tunc T, et al. Incidence, risk factors and severity of retinopathy of prematurity in Turkey (TR-ROP study): a prospective, multicentre study in 69 neonatal intensive care units. Br J Ophthalmol 2018;102:1711-6. https://doi.org/10.1136/bjophthalmol-2017-311789.

[26]Braimah I, Enweronu-Laryea C, Sackey A, Kenu E, Agyabeng K, Ofori-Adjei I, et al. Incidence and risk factors of retinopathy of prematurity in Korle-Bu Teaching Hospital: a baseline prospective study. BMJ Open 2020;10:e035341. https://doi.org/10.1136/bmjopen-2019-035341.

[27] AlBalawi H, AlBalawi N, AlSuhaimi N, AlBalawi A, AlAtawii A, Mirghani H, et al. Incidence and risk factors for retinopathy of prematurity in Tabuk city, KSA. Middle East Afr J Ophthalmol 2020;27:105-9. https://doi.org/10.4103/meajo.MEAJO_195_19.

[28]Carroll L, Owen L. Current evidence and outcomes for retinopathy of prematurity prevention: insight into novel maternal and placental contributions. Explor Med 2020;1:26. https://doi.org/10.37349/emed.2020.00002.

[29] Chow L, Wright K, Sola A, CSMC Oxygen Administration Study Group. Can changes in clinical practice decrease the incidence of severe retinopathy of prematurity in very low birth weight infants? Pediatrics 2003;111:339-45. https://doi.org/10.1542/peds.111.2.339.

[30]Tolsma K, Allred E, Chen M, Duker J, Leviton A, Dammann O. Neonatal bacteremia and retinopathy of prematurity: the ELGAN study. Arch Ophthalmol 2011;129:1555-63.

[31] Stoll B, Hansen N, Adams-Chapman I, Fanaroff A, Hintz S, Vohr B, et al. Neurodevelopmental and growth impairment among extremely low-birth-weight infants with neonatal infection. JAMA 2004;292:2357-65. https://doi.org/10.1001/jama.292.19.2357.

[32] Csak K, Szabó V, Vanny Á. Pathogenesis and genetic basis for retinopathy of prematurity. Frontiers in Bioscience : A Journal and Virtual Library 2006;11:208-20.

[33]Bernstein I, Horbar J, Badger G, Ohlsson A, Golan A. Morbidity and mortality among very-low-birth-weight neonates with intrauterine growth restriction. The Vermont Oxford Network. Am J Obstet Gynecol 2000;182:198-206. https://doi.org/10.1016/s0002-9378(00)70513-8.

[34]Filho J, Valiatti F, Eckert G, Costa M, Silveira R, Procianoy R. Is being small for gestational age a risk factor for retinopathy of prematurity? A study with 345 very low birth weight preterm infants. J Pediatr (Rio J) 2009;85:48-54. https://doi.org/10.2223/JPED.1870.

[35] Darlow B, Hutchinson, JL Henderson-Smart, DJ Donoghue D, Simpson J, Evans N, Australian and New Zealand Neonatal Netwok. Prenatal risk factors for severe retinopathy of prematurity among very preterm infants of the Australian and New Zealand Neonatal 
Network. Pediatrics 2005;115:990-6. https://doi.org/10.1542/peds.2004-1309.

[36] Kavurt S, Özcan B, Aydemir O, Bas A, Demirel N. Risk of retinopathy of prematurity in small for gestational age premature infants. Indian Pediatr 2014;51:804-6. https://doi.org/10.1007/s13312-014-0506-9. 